\title{
Copyright Form
}

\section{Indian Journal of Clinical Research in Dentistry (IJCRD)}

Manuscript Number:

-Manuscript Title:

Author declaration: I/ We declare that

1. Manuscript submitted was completely authenticated and approved by the Institutional Ethical/Research committee and experimental/clinical studies registered under Clinical Trial Registry of India (CTRI) would be appreciated and encouraged. 2. the manuscript is thoroughly evaluated and checked for plagiarism before submission. 3. Work submitted to the Indian journal of clinical research in dentistry is original, not submitted elsewhere and not duplicated or reproduced from any other content that is already published or in the process of publishing in part or full. 4. All the data mentioned including tables, Figures, Graphs and Photographs have been not taken or copied from any other public sources/ textbooks or any other journals. 5. All the authors have equally contributed to the work submitted and also agree upon to all the copyright reserved by the Indian Journal of Clinical Research in Dentistry. 6. All the authors should mention their conflicts of interest in the manuscript and taken informed consent of the patients involved in the study.

I/We also declare and give consent to the Indian journal of clinical research in dentistry to have rights on the accepted manuscripts or contents to publish or reproduce in electronic or print format in the journal site. Necessary changes in the manuscript can be done prior to final acceptance by the corresponding author and corresponding author must be guarantor on behalf of the co-authors. I/we declare that names of the non contributor/participants are not mentioned. Authors should take the responsibility of the content mentioned in the manuscript. I/we also give rights to publish the author names in the sequence mentioned.

\section{Name Signature Date}

1.

2.

3.

4.

5.

6.

Corresponding author details: Mail Id:

Contact No:

NOTE: Signed scanned copy of the copyright form to be mailed to editor@ijijerd.in (8886157669) 